\title{
Special characters and symbols, transcription and glossing conventions
}

Shaowu does not have its own writing system, although some words are cognate of or identifiable with those in standard written Chinese. Since there are Shaowuspecific words of which the etyma are unknown or unattested in the extant literature, where there is uncertainty as to what the word may be, we follow the convention established in Sinitic linguistic circles by placing an empty circle $\bigcirc$ to represent the corresponding syllable in the lexical item. At the lower right side of the circle, we insert the standard Chinese character (in subscript) that matches the meaning of the unidentified Shaowu word or syllable, but which is not the etymon of that word or syllable.

For instance, the etyma of the Shaowu first, second and third personal pronouns are to this day a mystery. Notwithstanding several plausible theories that have been put forward, we represent them by empty circles:

$\begin{array}{llll}\text { First person singular } & \mathrm{O}_{\text {我 }} & {\left[\mathrm{xan}^{35}\right]} & \text { 'I' } \\ \text { Second person singular } & \mathrm{O}_{\text {你 }} & {\left[\mathrm{xien}^{35}\right]} & \text { 'you' } \\ \text { Third person singular } & \mathrm{O}_{\text {他/她/它 }} & {\left[\mathrm{xu}^{35}\right]} & \text { 'he'/ 'she'/ 'it' }\end{array}$

We use the International Phonetic Alphabet (IPA) to transcribe Shaowu sentences; individual syllable or words will appear in square brackets [ ] when they are mentioned in a text body, whereas sample sentences used to illustrate certain linguistic features will abide by the following rules:

(i) The first line contains Chinese characters and/or empty circles only;

(ii) The second line contains the IPA transcription of the Shaowu sentence;

(iii) The third line contains the glossing of each semantico-grammatical unit;

(iv) The fourth line contains the translation in English of the Shaowu sentence.

An example to illustrate this:

$\begin{array}{llll}\mathrm{O}_{\text {我 }} \text { 是 } & \text { 邵武 } & \text { 人 } \\ \operatorname{xan}^{35} & 6 i^{55} & \operatorname{ciau}^{213 ~ 21} \mathrm{u}^{55} & \operatorname{nin}^{22} \\ 1 S G & \text { be } & \text { Shaowu } & \text { person } \\ \text { 'I am from Shaowu.' } & \end{array}$

Note that Shaowu has a phonetically identical designation of the three forms in English of the third person singular pronoun (3SG) $\left[\mathrm{xu}^{35}\right]$, i.e., the human male 'he' $\left(\mathrm{O}_{\text {他 }}\right)$, the human female 'she' $\left(\mathrm{O}_{\text {她 }}\right)$, and non-humans which include the 


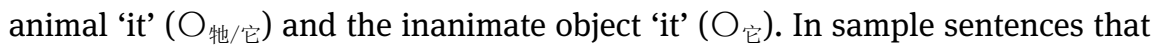
contain 3SG $\left[\mathrm{xu}^{35}\right]$, we only choose one semantic designation of the third person pronoun that corresponds to the context in which the utterance was made.

If a syllable or word has undergone tone change, which frequently occurs in natural or fast speech in Sinitic languages including Shaowu, we label it with a tilde $\sim$ (for tonal free variants) or a 'greater' sign $>$ (for phonological or morphological tone change) connecting the original tone value (to the left) with the mutated tone value (to the right), both in superscript, as illustrated by the character 邵 [6iau ${ }^{213 \sim 21}$ in the above example. Note that not every syllable or word will undergo tone change. In this book (cf. Chapter 3 on phonetics and phonology, § 3.2 Phonotactics), we indicate as many tone-change rules as we can. It is however to be borne in mind that exceptions to the rules exist.

All examples in Mandarin will be presented in pinyin, the standard transcription method adopted in the People's Republic of China in 1958 by the National People's Congress (see Hànyǔ pinyiñn fāng'àn 汉语拼音方案 ${ }^{4}$ [Scheme of the Chinese Phonetic Alphabet] for details). Any other Sinitic languages mentioned in this book will otherwise be transcribed in the IPA. Unless otherwise specified, all Chinese characters will appear in their simplified form.

$4 \mathrm{http}: / /$ www.moe.gov.cn/ewebeditor/uploadfile/2015/03/02/20150302165814246.pdf on the official website of the Ministry of Education of the People's Republic of China (last access on 20 July 2020). 